\title{
Strengthening the CAR-T Cell Therapeutic Application using CRISPR/Cas9 Technology
}

\author{
Muhammad Sadeqi Nezhad ${ }^{1}$, Mahboubeh Yazdanifar ${ }^{2}$, Meghdad Abdollahpour-Alitappeh³, \\ Arash Sattari $^{1}$, Alexander seifalian ${ }^{4}$, and Nader Bagheri ${ }^{5}$ \\ ${ }^{1}$ Islamic Azad University \\ ${ }^{2}$ Stanford University School of Medicine \\ ${ }^{3}$ Larestan University of Medical Sciences \\ ${ }^{4}$ University College London \\ ${ }^{5}$ Shahrekord University of Medical Science
}

May 9, 2021

\begin{abstract}
Adoptive cell immunotherapy with chimeric antigen receptor (CAR) T cell has brought a revolutionary means of treatment for aggressive diseases such as hematologic malignancies and solid tumors. Over the last decade, FDA approved three types of CAR$\mathrm{T}$ cells against CD19 hematologic malignancies, including Tisagenlecleucel (Kymriah), Axicabtagene ciloleucel (Yescarta), and Brexucabtagene autoleucel (Tecartus). Despite outstanding results gained from different clinical trials, CAR-T cell therapy is not free from side effects and toxicities, and needs careful investigations and improvements. Gene-editing technology, clustered regularly interspaced short palindromic repeats (CRISPR)/ CRISPR-associated protein 9 (Cas9) system has emerged as a promising tool to address some of the CAR-T therapy hurdles. Using CRISPR/Cas9 technology, CAR expression as well as other cellular pathways can be modified in various ways to enhance CAR-T cell's anti-tumor function and persistence in immunosuppressive tumor microenvironment. CRISPR/Cas9 technology can also be utilized to reduce CAR-T cells toxicity and side effects. Hereby, we discuss the practical challenges and hurdles related to the accuracy, efficiency, efficacy, safety and delivery of CRISPR/Cas9 technology to the genetically engineered-T cells. Combining of these two state-of-the-art technologies, CRISPR/Cas9 and CAR-T cells, the field of oncology has an extraordinary opportunity to enter a new era of immunotherapy, which offers novel therapeutic options for different types of tumors.
\end{abstract}

\section{Introduction}

Immunotherapy, which uses the patient's immune system to target and kill cancer cells, has become a promising tool for cancer treatment (Koury et al., 2018). Adoptive T cell therapy is a type of immunotherapy involving the isolation and in vitro expansion of patient-derived $\mathrm{T}$ cells and re-infusion into the cancer patients. In this context, peripheral blood $\mathrm{T}$ cells are used to produce genetically modified-T cells expressing transgenic T cell receptor, known as TCR and CAR-T cells (Met, Jensen, Chamberlain, Donia, \& Svane, 2019; Morgan, Dudley, \& Rosenberg, 2010). CAR T-cell, a living drug, has been investigated for more than two decades. Cumulative research data have demonstrated the remarkable success of CAR-T cells in some hematologic malignancies and solid tumors. In the beginning, CAR T-based therapy has been intensively used against hematologic malignancies, especially for patients with B-cell Acute Lymphoblastic Leukemia (B-ALL) (Sadeqi Nezhad et al., 2020). Consequently, FDA approved three CAR products, YESCARTA (axicabtagene ciloleucel), KYMRIAH (tisagenlecleucel), and TECARTUS (brexucabtagene autoleucel) to treat adult patients with certain types of large B-cell lymphoma, patients up to 25 years of age with Bcell precursor ALL, and patients with relapsed or refractory mantle-cell lymphoma. (S. L. Maude et al., 
2018; S. S. Neelapu et al., 2017; M. Wang et al., 2020). Three other potential CAR-T cells with an International Nonproprietary Name (INN), bb2121 (idecabtagene vicleucel), vadacabtagene leraleucel, and JCAR017 (lisocabtagene maraleucel) are expected to be approved for clinical use (Chow, Shadman, \& Gopal, 2018; D. W. Kim \& Cho, 2020; Rodríguez-Lobato et al., 2020).

CAR-T cells have several limitations that stop them from performing successfully and efficiently. Despite the tremendous clinical efficacy of CAR-T cell therapy in hematologic malignancies, there are multiple hurdles and barriers that restrict successful therapeutic outcomes. CAR-T cells found to have a limited persistence, proliferation, and expansion in some individuals, especially patients with CLL (Fraietta et al., 2018; Porter et al., 2015). Studies demonstrated that defects in intrinsic autologous T cells may prevent the success of CAR$\mathrm{T}$ cells in patients (Fraietta et al., 2018). In some cancer types (e.g., ALL), patients diagnosed with rapid progressive disease whom requires an immediate treatment with CAR-T cells, the therapy may fail due to the long-time autologous CAR-T manufacturing process. Additionally, adequate number of $\mathrm{T}$ cell collections from hematologic malignancy patients is sometimes laborious and impracticable due to lymphopenia from recent of prior chemotherapy or underlying disease (Singh, Perazzelli, Grupp, \& Barrett, 2016). Furthermore, CAR$\mathrm{T}$ therapy has also been used against solid tumors and showed promising therapeutic approaches; however, up to now FDA approved no CAR-T products for solid tumors. This signifies that the challenges in solid tumors are much more serious and require a thorough investigations. A major hurdle to the success of CAR-T cell therapy against solid tumors is tumor microenvironment and lack of tumor-specific antigen (K. B. Long et al., 2018).

By the advent of genome editing technology, such as CRISPR/Cas9, transcription activator-like effector nucleases (TALEN), and zinc finger nucleases (ZFNs), there is an opportunity to address many of these hindrances posed on CAR-T cell therapy (Berdien, Mock, Atanackovic, \& Fehse, 2014; Liu et al., 2017; J. Ren et al., 2017; Hiroki Torikai et al., 2010). Genome editing refers to the delivery of an editing machinery system in cells of interest to modify their genome either through the replacement of faulty genes or inserting new genes to treat diseases or boost the therapeutic outcomes (Gaj, Sirk, Shui, \& Liu, 2016). CRISPR/Cas9 has surpassed the two other genome editing systems in the following ways: (a) CRISPR/Cas9 recognizes the DNA site through RNA-DNA interaction; (b) is easy designing; (c) results in higher specificity and efficiency; (d) provides an easy way to manipulate multiple target DNA, simultaneously (high-yield multiplexing); and (e) is a budget-friendly technology (H. Li et al., 2020).

In the following sections, we will provide an overview of the CRISPR/Cas9 technology, challenges and barriers posed on CAR-T cell therapy, and finally methods thereby CRISPR/Cas9 system can potentially improve the success of CAR T-cell therapy.

\section{Overview of CRISPR/Cas9 Technology: Mechanism of Action as a Genome Editing Platform}

The immune system of many bacteria and almost all archaea harbor RNA-guided adaptive immune systems encoded by CRISPRs and CRISPR-associated (Cas) proteins to fight the invading bacteriophage or block the foreign plasmid transfer (Rath, Amlinger, Rath, \& Lundgren, 2015; Sorek, Lawrence, \& Wiedenheft, 2013). The short sequence of invading bacteriophage or plasmid DNA fragments stored in the CRISPR region is known as a protospacer sequence. The CRISPR RNA (crRNA) biogenesis process occurs upon the same entrance of pathogenic virus or plasmid in the future. The protospacer selected for transcription is based on protospacer adjacent motifs (PAMs) within the invading phage genomes and plasmids. These protospacer sequences, which serve as a genetic record of previously invaded viruses, transcribe into a long precursor (pre-crRNA) and subsequently form into mature crRNAs by endonucleolytic cleavage. Finally, the mature crRNA combines with Cas protein to generate a ribonucleoprotein complex structure that detects the target DNA by crRNA spacer and degrades the viruses and plasmids (Garcia-Robledo, Barrera, \& Tobón, 2020; Ishino, Krupovic, \& Forterre, 2018; Makarova et al., 2019).

There are different types of CRISPR systems. Among them, type II CRISPR locus recruits CRISPRassociated protein, Cas9, to produce double-stranded breaks (DSBs) in DNA of interest. Cas9 has a multitude of functions and is considered as a multi-functional protein. It possesses two distinct domains named HNH- 
nuclease and RuvC-like nuclease, which break the target DNA strand and the non-target DNA strand, respectively (Makarova \& Koonin, 2015; Wu, Kriz, \& Sharp, 2014). In genome engineering, the trans-activating CRISPR RNA (tracrRNA) and crRNA are engineered as a single-guided RNA (sgRNA), which is a 17-20 nucleotide sequence corresponding to the target DNA. To further simplify, CRISPR/Cas9 system is defined as sgRNA and Cas9 protein combination. sgRNA has a PAM sequence after the 3' end of its sequence (5'NGG-3' for streptococcus pyogenes (Sp)-Cas9), which is essential for guiding the Cas9 protein to the target DNA wherein the complementary PAM sequence is present. Upon the interaction between the sgRNA and the target DNA, the Cas9 protein generates a DSB from three nucleotides upstream of the PAM sequence (Cao, Xiao, \& Yan, 2018; Fonfara et al., 2014; Xiao-Jie, Li-Juan, Koo, \& Kim, 2017). Afterward, DSBs undergo two different mechanisms of repairs, homologous directed repair (HDR) and non-homologous end joining (NHEJ). The former approach is used to knock-in a specific DNA that creates either an aberrant gene to develop a specific disease or repair a particular defective gene with homologous DNA. The NHEJ system is error-prone and a quick fix mechanism throughout the cell cycle (Allen et al., 2019; Jasin \& Rothstein, 2013). This pathway requires no homologous sequence for ligation of DNA end and generates frameshift mutations through insertion and/or deletion (indel) mutations at the repair junctions (Figure 1 ). Once the DSB is induced, certain proteins, named Ku70 and Ku80, quickly bind to the DSB end and form the $\mathrm{Ku}$ heterodimer. The Ku complex forms a ring-shape to serve as a scaffold to recruit the NHEJ pathway molecules (Bischoff, Wimberger, Maresca, \& Brakebusch, 2020).

\section{Overview of CAR-T Cells}

In recent years, CAR-T cell emergence has revolutionized the cancer immunotherapy, particularly against refractory hematological malignancies (Sadelain, 2017) In this approach, patient's own T cells are genetically modified to express a synthetic receptor (CAR) linking antibody binding domains ( $\mathrm{scFv}$ ) with $\mathrm{T}$ cell's activation and costimulatory molecules. This chimeric molecule is able to bind a specific tumor antigen and transmit signals through intracellular domains leading to activation and cytotoxic function of $\mathrm{T}$ cells $(\mathrm{D}$. Li et al., 2019).

Currently the most commonly used strategy for generating CAR-T cells is harvesting patient's derived autologous $\mathrm{T}$ cells, transducing them with CAR gene normally embedded in viral vectors, and then infusing back into the patient after lymphodepleting therapy (Poorebrahim et al., 2021). This process involves high level of variability and potential manufacturing failure due to low quality of cancer patient's autologous $\mathrm{T}$ cells. Also, there is the risk of insertional mutagenesis caused by randomly integrating viral vectors. Moreover, in case of leukemias, blood- derived $\mathrm{T}$ cells might be contaminated with leukemic cells (Han, $\mathrm{Xu}$, Zhuang, Ye, \& Qian, 2021). Therefore, there are several manufacturing challenges that can affect the quality of CAR-T cell products (Marofi et al., 2021). Generating CAR-T cells through genome editing with CRISPR/Cas9 might address these challenges, and simultaneous TCR-knock out in T cells provides the opportunity to develop safe allogeneic T cell therapy (Roth et al., 2018).

\section{Principle of CRISPR/Cas9 system gene delivery into $\mathrm{T}$ cells}

The delivery of CRISPR/Cas9 to edit the genome of interest is defined into three distinct strategies. The first approach is using plasmid DNA encoding the Cas9 protein and sgRNA from the same vector. The second format is to deliver the mixture of the Cas9 mRNA and the sgRNA. The last strategy is a ribonucleoprotein (RNP), the complex of Cas9 protein and sgRNA, which is considered advantageous compared to the two other systems (Luther, Lee, Nagaraj, Scaletti, \& Rotello, 2018). The RNP method does not require the delivery of foreign DNA and the complex of Cas9-gRNA degrades over time, which may minimize the offtarget effects. RNP-based delivery displayed a fast, efficient and cost-effective method to modify the genome of the target. Another advantage of using RNP is the variety of methods that can be used to deliver the Cas9-gRNA complex, including electroporation (Gundry et al., 2016).

Although the first strategy of delivery, plasmid-based CRISPR-Cas9 system, is a simple and straightforward approach, it tends to cause off-target mutation in primary T cells (Kornete, Marone, \& Jeker, 2018). The plasmid-based system encounters several challenges. Upon the entering of plasmid into the desired nucleus, 
it undergoes the transcription and translation processes to express the encoded proteins. These processes require more time to effectively target the gene of interest (Fujihara \& Ikawa, 2014). More importantly, this format of delivery was found to result in an irreversible off-target cleavage site (Cradick, Fine, Antico, \& Bao, 2013; Fu et al., 2013). The other negative aspect of the plasmid-based approach is its size limitation, as many current vectors have restrictions for large-sized genes. Moreover, transfection of plasmid DNA may activate the cyclic GMP-AMP synthase and as a consequence leads to host immunogenicity (Xu et al., 2019).

The second strategy is direct delivery of Cas9 mRNA and sgRNA into the target cells to form a Cas9/sgRNA complex inside the cells. One advantage of this approach is the use of mRNAs that can be translated in the cytoplasm, therefore requiring intracellular delivery which is much more convenient rather than delivery to the nucleus. Furthermore, mRNA translation process reduces required time for genome editing. Besides, mRNA-based delivery demonstrated a low rate of off-target effects compared to the plasmid DNA strategy. However, this approach is limited because mRNA is fragile and may get degraded during the delivery or preparation process (Givens, Naguib, Geary, Devor, \& Salem, 2018; Shen et al., 2014).

The last form of CRISPR/Cas9 delivery is RNP. This approach avoids the processes of transcription and translation, and provides the fastest means of gene editing compared to the other two methods (Schumann et al., 2015; Seki \& Rutz, 2018). The delivery of RNP gives a myriad of advantages including the less off-target effect due to the fast degradation of Cas9 nuclease and no need for codon optimization and promoter selection (Hendel et al., 2015; Liang et al., 2015). RNP editing is very rapid, and indels can be measured after 3-24 hours. Cas9 protein is rapidly degraded from cells within $24 \mathrm{~h}$, compared to the plasmid electroporation method that persists nearly 73h (Sojung Kim, Kim, Cho, Kim, \& Kim, 2014).

Currently, several non-viral nanovectors are used for RNP delivery into the cells in vitro, including DNA nanoclews (the yarn-like DNA nanoparticles synthesized by rolling circle amplification), cationic lipid nanoparticles and lipoplexes (cationic liposomes, composed of nonviral (synthetic) lipid carriers of DNA), gold-based nanoparticles, and zeolitic imidazole frameworks (Wei, Cheng, Min, Olson, \& Siegwart, 2020; Xu et al., 2019).

CRISPR/Cas9 system can be applied either before the generation of CAR-T cells or after the production of CAR-T cells, as it is illustrated inFigure 2 . Currently, RNP delivery of CRISPR/Cas9 technology into the $\mathrm{T}$ cells represented as a promising approach compared to the other methods of delivery. $\mathrm{T}$ cells have been targeted by lentiviral and adenoviral for delivery of CRISPR components. These deliveries seem to be ineffective due to low gene disruption efficiency, feeble site-specificity insert, and randomly disruption of unwanted genes (C. Li et al., 2015; W. Wang et al., 2014). The in vivo transfection of CRISPR/Cas9 model encounters different problems, including low disruption efficiency, insertional mutagenesis, off-target effects, toxicity and immunogenicity (Lino, Harper, Carney, \& Timlin, 2018; Mout, Ray, Lee, Scaletti, \& Rotello, 2017). These adverse effects will be explored later in the next section.

\section{CRISPR/Cas9 system generates off-the-shelf CAR-T cells}

Lymphocytes used in genetically modified-T cell therapies are dominantly derived from patient's autologous $\mathrm{T}$ cells. This source of $\mathrm{T}$ cells has limitations including having insufficient number of $\mathrm{T}$ cells, time-consuming and laborious isolation process (Sharpe \& Mount, 2015). These hurdles have brought the concept of universal or off-the-shelf $\mathrm{T}$ cells, wherein the allogeneic $\mathrm{T}$ cells derived from third party donors are genetically manipulated and can be used for different patients. Using allogeneic $\mathrm{T}$ cells as the main source of $\mathrm{T}$ cells in CAR-based therapy is not simple. The infused allogeneic T cells expressing $\alpha \beta$ TCR can recognize the recipient's cells as foreign and destroy them, leading to a phenomenon known as graft versus host disease (GVHD). (Ju et al., 2005; Townsend, Bennion, Robison, \& O'Neill, 2020).

Several factors are found to promote the development of GVHD, including human leukocyte antigen class I (HLA-I) mismatched related donor or HLA matched unrelated donor. The most important factor is beta-2microglobulin $(\beta 2 \mathrm{M})$, a pivotal subunit of HLA-I protein that plays a key role in the removal of allogeneic cells expressing non-self HLA-I molecules in the recipient (Salas-Mckee et al., 2019; H. Torikai et al., 2013). Therefore, knocking out endogenous TCR and HLA (or $\beta 2 \mathrm{M}$ ) as two crucial receptors of T cells may realize 
the development of off-the-shelf CAR-T cells by eliminating the risk of GVHD.

Eyquem et al. disrupted T-cell receptor $\alpha$ constant (TRAC) locus through sgRNA targeting the 5' end of the first exon of TCR $\alpha$, and using adeno-associated virus (AAV) vector encoding the promoter-CAR-polyA cassette flanked by homology arms to knock in the CD19 CAR gene. Nearly $95 \%$ of transfused CAR ${ }^{+}$T cells were negative for TCR expression. NALM-6 mouse with pre-B acute lymphoblastic leukemia was introduced with $1 \times 10^{5}$ doses of CD19 TRAC-CAR T-cells, which successfully achieved tumor control, and just $2 \%$ of these cells expressed exhaustion or co-inhibitory receptors such as PD1, LAG3, and TIM3, and maintained more effector memory phenotypes. The low expression of inhibitory receptors is mainly associated with greater in vivo anti-tumor activity and resulted in superior tumor eradication. These results underscore that TRAC has a pivotal role in the regulation of CAR expression in two different ways. One is by enhancing the optimal baseline expression, which participates in CAR internalization upon either the interaction with antigens or receiving signals. The other is the recovery of baseline CAR expression upon exposure to the antigen by controlling the transcriptional response. More importantly, targeting of TCR locus may mitigate the probability of insertional oncogenesis and TCR-induced autoimmunity and alloreactivity, leading to safer modified-T cells and resulting in perpetual CAR expression. Hence, this study depicted that how by genome editing technology, a $\mathrm{T}$ cell-based therapy can be improved and yield a robust treatment (Eyquem et al., 2017).

Likewise, Ren et al. have knocked out three different genomic loci, including TCR, $32 \mathrm{M}$, and PD-1 simultaneously in human $\mathrm{T}$ cells via CRISPR/Cas9 system electroporation. They introduced CAR transgene through lentiviral transduction and generated allogeneic CAR-T cells deprived of TCR, HLA-I, and PD-1, are known as universal CAR T-cells. The targeting efficiency of sgRNA yielded over $90 \%$, and the disruption of HLA-I and TCR resulted in a low rapid rejection of CAR-T cells in allogeneic recipients. Also, it did not lead to GVHD in in vivo model. The anti-tumor activity of CAR-T cells increased substantially by knocking PD-1expression out. One significant concern of this study is that triple loci-knocked out CAR-T cells may trigger the NK cell activation due to the absence of HLA-I in CAR T-cells. NK cell specific antibody or NK cell depletion via chemotherapy may potentially avoid or mitigate NK mediated rejection of transferred HLA-I negative CAR-T cells (Jiangtao Ren, Xiaojun Liu, et al., 2017).

Inconsistent with these data, Georgiadis et al. introduced human T cells with lentiviral vector encoded CD19 CAR and sgRNA targeting the TRAC region, and Cas9 mRNA was delivered by electroporation. $5 \times 10^{5}$ of CD19-CAR TCR- T-cells infused into the humanized murine model of Daudi B cell leukemia resulted in significant clearance of tumors, with no GVHD and no evidence of the overexpression of engineered T cell's exhaustion markers such as PD-1. (Georgiadis et al., 2018).

Similarly, CRISPR/Cas9 was applied to CD19 CAR-T cells to ablate the constant TCR $\beta$-chain. CD19 CAR-T cells lacking TCR were highly functional and showed no alloreactivity in patient-derived xenografts of $\mathrm{CD} 19^{+}$childhood ALL in a murine model (Stenger, Stief, Käuferle, et al., 2020). These studies suggest that CRISPR/Cas9 technology can be used as a promising tool for the development of off-the-shelf CAR-T cells by knocking out the TCR and $\beta 2 \mathrm{M}$ loci in allogeneic T cells, and further it can lead to remarkable GVHD reduction and alloreactivity by TCR disruption.

\section{Development of CAR-T cells that are resistant to suppressive molecules}

The expression of inhibitory receptors such as cytotoxic T lymphocyte-associated antigen 4 (CTLA-4), T-cell membrane protein 3 (TIM-3), lymphocyte activation gene 3 (LAG-3), and programmed cell death protein-1 (PD-1) on T cells control and restrict T cell activities and responses (L. Long et al., 2018). These inhibitory molecules mitigate the immune responses and cause exhaustion of $\mathrm{T}$ cells. The exhausted $\mathrm{T}$ cells have altered transcriptional program which distinguishes them from memory and prototypic effector $\mathrm{T}$ cell populations (Wherry \& Kurachi, 2015).

Tumors can suppress the immune responses and escape from immune cells by expressing negative regulatory pathways, known as immune checkpoints. One important key player of the immune checkpoints is PD-1, a type I transmembrane receptor inhibiting T cell proliferation and performance (Seliger, 2019). PD-1 is 
normally expressed on the surface of activated T cells, and its interaction with cognate ligands, PDL1 and PDL2, limits T cell activity and inhibits excessive stimulation, which leads to an immune escape for tumor cells (Zak et al., 2015). PD-1 expression by CAR-T cells has the same deteriorating impact; therefore, disrupting PD-1 can boost $\mathrm{T}$ cell anti-tumor responses (Table 1).

In addition, Fas receptor (CD95), a cell surface protein that belongs to the tumor necrosis factor $\alpha$ family of death receptors, contributes to the regulation of $\mathrm{T}$ cell activity. Interaction of Fas molecule with its ligand (FasL) induces the $\mathrm{T}$ cell apoptosis cascades which may reduce the engineered $\mathrm{T}$-cell response via inducing the activation-induced cell death (AICD) (Jiangtao Ren, Xuhua Zhang, et al., 2017).

Rupp et al . have transfected human T cells with Cas9 and sgRNA targeting PD-1 exon 1 through electroporation and subsequent introduction of lentiviral vector containing the CD19 CAR transgene. CD19+ PD-L1 ${ }^{+}$tumor xenograft models were injected with $4 \times 10^{6} \mathrm{PD}$-1-deficient CD19 CAR-T cells and resulted in clearance of tumors in all treated mice. This finding highlights the suppressive role of the PD-1/PD-L1 axis on CAR-T cells upon the engagement with the antigen of interest on tumor cells. Further, the study revealed the applicability of CRISPR-Cas9 genome editing as a viable tool for the enhancement of CAR T-cell performance (Rupp et al., 2017).

In contrast to the previous study wherein $\mathrm{T}$ cells were transfected at least twice using a combination of electroporation and lentiviral transduction, a new study transfected T cells using plasmids encoding Cas9, PD-1 targeting sgRNA, and the piggyBac transposon vector encoding CD133-CAR in one reaction via nucleofection process. This method led to $89.5-95 \%$ insertions and deletions in PD-1 gene site. $2 \times 10^{6}$ doses of PD-1-deficient CD133 CAR-T cells were infused to the orthotopic glioma xenografts in immunodeficient mice and led to outstanding outcomes. The modified T-cells demonstrated persistence and the survival of mice was enhanced. Besides, no sign of GVHD and CAR T related side effects and aberrant proliferation of PD-1-deficient modified T-cells were detected due to the rapid elimination of these modified T-cells within 28 days, highlighting the role of PD-1 in the survival of CAR T-cells. Importantly, this study highlighted the use of plasmid DNA as a more efficient approach due to the low cost and easier preparation compared to the RNA, protein and virus delivery methods (B. Hu et al., 2019). Other studies are also consistent with these findings (W. Hu et al., 2019; Nakazawa et al., 2020).

More encouragingly, Choi et al. exerted the CRISPR-Cas9 system application to EGFRVIII CAR-T cells in which three different loci including PD-1, $\beta 2 \mathrm{M}$ and TRAC regions were targeted to generate universal CAR modified-T cells resistant to PD-1 suppression. T cells were electroporated with CRISPR/Cas9 complex targeting TRAC and $\beta 2 \mathrm{M}$ and Pdcd1 loci and were subsequently transduced with adeno-associated virus encoding the EGFRVIII CAR. More than $80 \%$ of the T cell population was double knocked out for surface expression of TCR and HLA-I. $5 \times 10^{3}$ triple gene-deficient EGFRvIII CAR-T cells were administered through intravenous delivery or intraventricular infusion in murine models of human GBM. The former route of delivery did not significantly increase the survival rate of mice, while the latter means of infusion showed to be more efficacious against the GBM mice model. The triple gene-deficient EGFRvIII CAR-T cells also depicted highly anti-tumor response in preclinical glioma models (Choi et al., 2019).

\section{CRISPR/Cas9 technology enhances CAR T-cell performance in solid tumors}

The efficacy of CAR T-cell therapy towards solid tumors has been severely restricted by some physical and physiological barriers, such as tumor microenvironment (TME) hypoxia, acidic environment, and nutritional deficiency and presence of immunosuppressive cells (regulatory $\mathrm{T}$ cells, myeloid-derived suppressor cells, and tumor-associated macrophages and neutrophils) (Yazdanifar, Zhou, \& Mukherjee, 2016). Solid tumors create a complex zone containing many cell types, tumor's vasculature, extracellular matrix components, connective tissues, and inflammatory mediators which can impair $\mathrm{T}$ cells infiltration and function (Joyce \& Fearon, 2015; Turley, Cremasco, \& Astarita, 2015).

Other factors which hamper the efficacy of CAR-T cells include suppressive molecules (Indoleamine 2,3dioxygenase (IDO) (Yazdanifar et al., 2019), transforming growth factor-beta (TGF-b), PDL1, IL-10 and 
arginase-1), immunosuppressive inhibitor receptors, soluble factors (prostaglandin E2 and indoleamine-2,3dioxygenase) (Anderson, Stromnes, \& Greenberg, 2017; J. H. Chen et al., 2015; Koyama et al., 2016).

To overcome the hostile TME, recently, a group of researchers successfully disrupted the endogenous TGF- $\beta$ receptor II (TGFBR2) gene in modified T-cells expressing mesothelin CAR, using CRISPR/Cas9 technology. The modified T cells diminished the induced Treg conversion and restrained the exhaustion. TGF- $B$ knockout mesothelin CAR-T cells eradicated the tumor cells completely by day 28 in pancreatic carcinoma patientderived xenograft models expressing mesothelin and TGF-ß1receptors. This study further shed light on the negative regulatory role of TGF- $\beta$ receptors in CAR T-cell cytotoxicity responses. It also highlighted that disruption of the TGFBR2 gene would enable modified T-cells to survive and proliferate effectively and exert higher anti-tumor activity. Encouragingly, it was shown that knocking out of other immune checkpoints such as PD-1 simultaneously with TGF-B1 may lead to a better therapeutic outcome in CAR T-cell therapy (Tang et al., 2020).

Diacylglycerol kinases (DGKs) is an enzyme that phosphorylates diacylglycerol (DAG) signaling to encourage phosphatidic acid (PA) production. Both DAG and PA are bioactive molecules that regulate a multitude of intracellular signaling proteins involved in innate and adaptive immunity (S. S. Chen, Hu, \& Zhong, 2016). Upon the interaction between TCR on T cells and antigen presenting cells, a cascade of signaling initiates by the activation of phospholipase $\mathrm{C} \gamma 1$ ( $\mathrm{PLC} \gamma 1$ ), which cleaves phosphatidylinositol-4,5-biphosphate $\left(\mathrm{PIP}_{2}\right)$ to form the second messengers DAG and inositol triphosphate $\left(\mathrm{IP}_{3}\right)$ (Baldanzi, Bettio, Malacarne, \& Graziani, 2016). DAG plays an important role in activation of different downstream signaling pathways, such as AKT, NF-kB, and Ras pathways. The vital role of DGKs is to control DAG metabolism in T cells. Two DGK

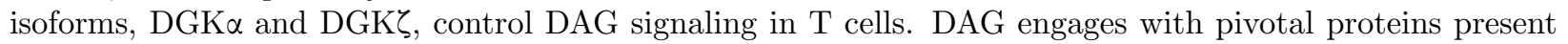
in CD3 signaling such as Ras activating protein (RasGRP1) and protein kinase C (PKC); thus, activation of DGK leads downregulation of TCR distal molecules via metabolizing DAG at immune synapse (Riese, Moon, Johnson, \& Albelda, 2016). Accordingly, DGKs control T cell polarization and function during migration and activation, anergy, and response to tumor cells.

The production of CARs with appropriate signaling mechanism is an essential issue to boost the cellular activation, persistence, cytokine secretion, and cytotoxicity of CAR-T cells. Since DGKs participate in T cell signaling, a group of researchers used CRISPR/Cas9 genome editing technology to disrupt DGK in CAR$\mathrm{T}$ cells. Findings revealed that DGK-deficient CAR-T cells were significantly more resistance to soluble immunosuppressive components such as prostaglandin E2 and TGF- $\beta$ in in vivo model. DGK-deficient CAR$\mathrm{T}$ cells had increased effector functions in vitro and robust TCR signaling. This finding clearly suggested that DGKs can be considered as a potential therapeutic component to tackle suppressive factors present in solid tumors that prevent CAR T-cell activities (Jung et al., 2018).

\section{CRISPR/Cas9 technology can reduce CAR-T cells associated toxicities}

Although CAR T-cell therapy is demonstrated as a promising therapeutic option for different cancers, this novel treatment is not exempt from adverse events, and needs thorough consideration to tackle its limitations. One potential adverse event is on-target off-tumor effects, where CAR-T cells target the healthy tissues sharing the same epitope of antigen (Jung \& Lee, 2018). Second adverse event is cytokine release syndrome (CRS), which mostly occurs by proinflammatory cytokines such as granulocyte-macrophage colony-stimulating factor (GM-CSF), monocyte chemoattractant protein-1(MCP-1), TNF- $a$, IL-6, IFN- $\gamma$, and IL-2 (Shannon L Maude et al., 2018; Sattva S Neelapu et al., 2017; Park et al., 2018). One eminent strategy to tackle these obstacles is the use of CRISPR/Cas9 gene-editing technology.

Sterner et al. applied the CRISPR/Cas9 system armed with sgRNA targeting GM-CSF in CD19 CAR-T cells to control the CAR-T associated toxicities. These GM-CSF-deficient CD19 CAR-T cells reduced the GM-CSF secretion and enhanced the anti-tumor effect with low side effects of CRS and neurotoxicities in leukemia NALM6 xenograft model (Sterner et al., 2019). This study clearly proposed that GM-CSF is associated with CRS; thus, future studies need to target this gene to reduce the side effects.

CRISPR/Cas9 can be utilized to generate safer and more controllable CAR-T cells by adding inducible safety 
switches or suicide genes which provide a tool for eliminating CAR-T cells in case of potential toxicities. An inducible Cas9-based suicide gene was incorporated in IL-15-expressing CD19 CAR-T cells by Hoyos et $a l$. and their results confirmed that $>95 \%$ of CAR-T cells could be efficiently ablated within 24 hours upon pharmacologic activation of the suicide gene (Hoyos et al., 2010). Currently, there are three clinical trials (NCT02107963, NCT01822652, and NCT02439788) incorporating the Cas9-based suicide gene into CAR-T cell products to provide a means for eliminating the autologous CAR-T cells in case of unexpected offtarget toxicity. Insertion of safety switches in CAR construct is another approach to terminate the adverse effects without jeopardizing clinical responses. Inducible Cas9-based safety switch was tested in a CD19 CAR-T cells and results confirmed its feasibility for eliminating CAR-T cells in a dose dependent manner in a humanized mouse model (Diaconu et al., 2017). This approach allows for both selective suppression of CAR-T cell activation in a case of CRS, and also complete depletion on demand.

As discussed here, many limitations of conventional CAR-T cells can be addressed using CRISPR/Cas9. However, there are concerns surrounding the safety of using these gene-edited cells in clinic and careful investigation must be applied. Several factors such as off-target effects, unintended mutations and unwanted Cas9 activity can affect the safety of CRISPR/Cas9 system (S. Kim et al., 2018). Besides, CRISPR/Cas9 might alter the function of gene-edited CAR-T cells which could lead to the activation of unintended innate/adaptive immune responses (S. Kim et al., 2018). Although these events are rare, they can cause adverse effects in patients and need to be addressed in gene-edited $\mathrm{T}$ cells before clinical use.

\section{Perspective and future direction}

Here, we reviewed studies highlighting the promising impact of new technologies in cancer immunotherapy (Figure 3 ). Editing CAR-T cells with CRISPR/Cas9 can overcome many challenges such as allogeneic reaction, tonic signaling, exhaustion, low performance in TME and toxicity. In addition, the large-scale genetic screens using the CRISPR/Cas9 system provides scalable methods to interrogate thousands of genes in $\mathrm{T}$ cells with high efficiency and specificity.

TCR and HLA knocked out T cells present great potential for developing allogeneic third-party $\mathrm{T}$ cell products. However, there is controversy over benefits of TCR deletion. In a recent study, TCR $\beta$ knocked-out CD19 CAR-T cells were compared to TCR intact CD19 CAR-T cells (Stenger, Stief, Kaeuferle, et al., 2020). Although knocking out the endogenous TCR in CAR-T cells strongly eliminated alloreactivity compared to TCR-expressing CAR-T cells; co-expression of endogenous TCR plus CAR led to superior persistence of T cells and significantly extended the control of leukemia in vivo. This data highlights that despite the benefits of TCR knocked out T cells in developing off-the-shelf cell therapies, presence of endogenous TCR might be better for long-term survival of T cells. Hence, a deeper understanding of T cell biology and TCR signaling provides useful insights for designing and engineering more effective CAR-T cells.

CRISPR/Cas9 technology can also indirectly assist in developing more effective CAR-T cell therapies. Using large scale CRISPR screening libraries, we can discover novel antigens to be targeted by CAR-T cells. Moreover, we can identify factors in T cells, tumor cells or TME which induce resistance to CAR-T cells (Dufva et al., 2020). By genome-wide genetic perturbation/CRISPR screen, Dufva et al. investigated genes which their loss in cancer cells impaired the effector function of CAR-T cells and revealed the essentiality of death receptor signaling for CAR-T cell cytotoxicity. Similar studies provide a better understanding of mechanisms influencing CAR-T cell function and the potential for modulation using combination therapy or genetic engineering strategies.

Although recently emerged, CRISPR/Cas9 nowadays is a "go to" method for gene editing in many research labs in academic and pharmaceutical industry. With this fast advancement in the CRISPR/Cas9 application and emergence of new gene-editing technologies, we hope to soon witness the success of CAR-T cells in treating many refractory cancers including solid tumors.

\section{Conclusion}

There are challenges associated with CAR-T cell therapy that can be addressed by genome editing technology. 
CRISPR/Cas9 has been a helpful tool for the success of CAR-T cell therapy against different tumor cells. This novel genome-editing technology addressed the problem lies in the clinical use of allogeneic donor $\mathrm{T}$ cells, which led to GVHD in the recipient. CRISPR/Cas9 can reduce the potential GVHD caused by allogeneic CAR-T cells through eliminating TRAC and HLA loci. This approach would draw the concept of the development of off-the-shelf CAR-T cells, which could be applied in different individuals regardless of HLA matches between donor and recipient. CAR-T cell performance has been improved by disrupting inhibitory molecules, such as PD-1 and TGF- $\beta$. Given the early positive outcome of the CRISPR/Cas9 edited CAR-T cells, there appear to be numerous opportunities for new cancer therapy. The annual market value for successful cancer therapy exceed billions of US dollars, and this encourages academic as well as the pharmaceutical industry further research into this technology for the treatment of unmet clinical need in many diseases.

\section{Acknowledgements}

The authors would like to acknowledge the reviewers for their helpful and constructive comments on this manuscript.

\section{Conflict of interest}

Authors stated that there is no conflict of interest.

\section{Authors contribution}

All Authors contributed to the study conception and design. Data acquisition: M.SN, M.AA, Alexander.S, and AS. Quality control of data and algorithms: M.Y, N.B, M.AA, and M.SN. Data analysis and interpretation: M.SN, Alexander.S, A.S, and M.AA. Manuscript preparation: M.SN, M.Y, A.S, Alexander.S, and M.AA. Manuscript editing: M.SN, N.B, A.S, and Alexander.S. Manuscript review: M.SN, M.AA, N.B, and Alexander.S. All authors read and approved the final manuscript.

\section{References}

Allen, F., Crepaldi, L., Alsinet, C., Strong, A. J., Kleshchevnikov, V., De Angeli, P., . . . Kosicki, M. (2019). Predicting the mutations generated by repair of Cas9-induced double-strand breaks. Nature biotechnology, $37(1), 64-72$.

Anderson, K. G., Stromnes, I. M., \& Greenberg, P. D. (2017). Obstacles posed by the tumor microenvironment to T cell activity: a case for synergistic therapies. Cancer cell, 31 (3), 311-325.

Baldanzi, G., Bettio, V., Malacarne, V., \& Graziani, A. (2016). Diacylglycerol Kinases: Shaping Diacylglycerol and Phosphatidic Acid Gradients to Control Cell Polarity. Frontiers in cell and developmental biology, 4 , 140. doi:10.3389/fcell.2016.00140

Berdien, B., Mock, U., Atanackovic, D., \& Fehse, B. (2014). TALEN-mediated editing of endogenous T-cell receptors facilitates efficient reprogramming of T lymphocytes by lentiviral gene transfer.Gene therapy, 21 (6), 539-548. doi:10.1038/gt.2014.26

Bischoff, N., Wimberger, S., Maresca, M., \& Brakebusch, C. (2020). Improving Precise CRISPR Genome Editing by Small Molecules: Is there a Magic Potion? Cells, 9 (5). doi:10.3390/cells9051318

Cao, J., Xiao, Q., \& Yan, Q. (2018). The multiplexed CRISPR targeting platforms. Drug Discovery Today: Technologies, 28, 53-61.

Chen, J. H., Perry, C. J., Tsui, Y.-C., Staron, M. M., Parish, I. A., Dominguez, C. X., . . . Kaech, S. M. (2015). Prostaglandin E2 and programmed cell death 1 signaling coordinately impair CTL function and survival during chronic viral infection. Nature medicine, 21 (4), 327-334.

Chen, S. S., Hu, Z., \& Zhong, X. P. (2016). Diacylglycerol Kinases in T Cell Tolerance and Effector Function. Frontiers in cell and developmental biology, 4 , 130. doi:10.3389/fcell.2016.00130 
Choi, B. D., Yu, X., Castano, A. P., Darr, H., Henderson, D. B., Bouffard, A. A., . . . Gerhard, G. M. (2019). CRISPR-Cas9 disruption of PD-1 enhances activity of universal EGFRvIII CAR T cells in a preclinical model of human glioblastoma. Journal for immunotherapy of cancer, 7 (1), 1-8.

Chow, V. A., Shadman, M., \& Gopal, A. K. (2018). Translating anti-CD19 CAR T-cell therapy into clinical practice for relapsed/refractory diffuse large B-cell lymphoma. Blood, 132 (8), 777-781. doi:10.1182/blood2018-04-839217

Cradick, T. J., Fine, E. J., Antico, C. J., \& Bao, G. (2013). CRISPR/Cas9 systems targeting $\beta$-globin and CCR5 genes have substantial off-target activity. Nucleic acids research, 41 (20), 9584-9592.

Diaconu, I., Ballard, B., Zhang, M., Chen, Y., West, J., Dotti, G., \& Savoldo, B. (2017). Inducible Caspase9 Selectively Modulates the Toxicities of CD19-Specific Chimeric Antigen Receptor-Modified T Cells.Mol Ther, 25 (3), 580-592. doi:10.1016/j.ymthe.2017.01.011

Dufva, O., Koski, J., Maliniemi, P., Ianevski, A., Klievink, J., Leitner, J., . . . Mustjoki, S. (2020). Integrated drug profiling and CRISPR screening identify essential pathways for CAR T-cell cytotoxicity. Blood, 135 (9), 597-609. doi:10.1182/blood.2019002121

Eyquem, J., Mansilla-Soto, J., Giavridis, T., van der Stegen, S. J., Hamieh, M., Cunanan, K. M., . . . Sadelain, M. (2017). Targeting a CAR to the TRAC locus with CRISPR/Cas9 enhances tumour rejection.Nature, 543 (7643), 113-117.

Fonfara, I., Le Rhun, A., Chylinski, K., Makarova, K. S., Lecrivain, A.-L., Bzdrenga, J., . . . Charpentier, E. (2014). Phylogeny of Cas9 determines functional exchangeability of dual-RNA and Cas9 among orthologous type II CRISPR-Cas systems. Nucleic acids research, 42 (4), 2577-2590.

Fraietta, J. A., Lacey, S. F., Orlando, E. J., Pruteanu-Malinici, I., Gohil, M., Lundh, S., . . Melenhorst, J. J. (2018). Determinants of response and resistance to CD19 chimeric antigen receptor (CAR) T cell therapy of chronic lymphocytic leukemia. Nat Med, 24 (5), 563-571. doi:10.1038/s41591-018-0010-1

Fu, Y., Foden, J. A., Khayter, C., Maeder, M. L., Reyon, D., Joung, J. K., \& Sander, J. D. (2013). Highfrequency off-target mutagenesis induced by CRISPR-Cas nucleases in human cells. Nature biotechnology, $31(9), 822-826$.

Fujihara, Y., \& Ikawa, M. (2014). CRISPR/Cas9-based genome editing in mice by single plasmid injection. Methods Enzymol, 546 , 319-336. doi:10.1016/b978-0-12-801185-0.00015-5

Gaj, T., Sirk, S. J., Shui, S. L., \& Liu, J. (2016). Genome-Editing Technologies: Principles and Applications. Cold Spring Harb Perspect Biol, 8 (12). doi:10.1101/cshperspect.a023754

Garcia-Robledo, J. E., Barrera, M. C., \& Tobón, G. J. (2020). CRISPR/Cas: from adaptive immune system in prokaryotes to therapeutic weapon against immune-related diseases: CRISPR/Cas9 offers a simple and inexpensive method for disease modeling, genetic screening, and potentially for disease therapy. International Reviews of Immunology, 39 (1), 11-20.

Georgiadis, C., Preece, R., Nickolay, L., Etuk, A., Petrova, A., Ladon, D., . . Kim, D. (2018). Long terminal repeat CRISPR-CAR-coupled "universal" $\mathrm{T}$ cells mediate potent anti-leukemic effects.Molecular Therapy, 26 (5), 1215-1227.

Givens, B. E., Naguib, Y. W., Geary, S. M., Devor, E. J., \& Salem, A. K. (2018). Nanoparticle-Based Delivery of CRISPR/Cas9 Genome-Editing Therapeutics. Aaps j, 20 (6), 108. doi:10.1208/s12248-018-0267-9

Gundry, M. C., Brunetti, L., Lin, A., Mayle, A. E., Kitano, A., Wagner, D., . . Nakada, D. (2016). Highly Efficient Genome Editing of Murine and Human Hematopoietic Progenitor Cells by CRISPR/Cas9. Cell Rep, 17 (5), 1453-1461. doi:10.1016/j.celrep.2016.09.092

Han, D., Xu, Z., Zhuang, Y., Ye, Z., \& Qian, Q. (2021). Current Progress in CAR-T Cell Therapy for Hematological Malignancies. J Cancer, 12 (2), 326-334. doi:10.7150/jca.48976 
Hendel, A., Bak, R. O., Clark, J. T., Kennedy, A. B., Ryan, D. E., Roy, S., . . Wilkens, A. B. (2015). Chemically modified guide RNAs enhance CRISPR-Cas genome editing in human primary cells. Nature biotechnology, 33 (9), nbt. 3290.

Hoyos, V., Savoldo, B., Quintarelli, C., Mahendravada, A., Zhang, M., Vera, J., . . . Dotti, G. (2010). Engineering CD19-specific T lymphocytes with interleukin-15 and a suicide gene to enhance their antilymphoma/leukemia effects and safety. Leukemia, 24 (6), 1160-1170. doi:10.1038/leu.2010.75

Hu, B., Zou, Y., Zhang, L., Tang, J., Niedermann, G., Firat, E., . . . Zhu, X. (2019). Nucleofection with plasmid DNA for CRISPR/Cas9-mediated inactivation of programmed cell death protein 1 in CD133-specific CAR T cells. Human gene therapy, 30 (4), 446-458.

Hu, W., Zi, Z., Jin, Y., Li, G., Shao, K., Cai, Q., . . Wei, F. (2019). CRISPR/Cas9-mediated PD-1 disruption enhances human mesothelin-targeted CAR T cell effector functions. Cancer Immunology, Immunotherapy, $68(3), 365-377$.

Ishino, Y., Krupovic, M., \& Forterre, P. (2018). History of CRISPR-Cas from encounter with a mysterious repeated sequence to genome editing technology. Journal of bacteriology, 200 (7).

Jasin, M., \& Rothstein, R. (2013). Repair of strand breaks by homologous recombination. Cold Spring Harbor perspectives in biology, 5 (11), a012740.

Joyce, J. A., \& Fearon, D. T. (2015). T cell exclusion, immune privilege, and the tumor microenvironment. Science, 348 (6230), 74-80.

Ju, X. P., Xu, B., Xiao, Z. P., Li, J. Y., Chen, L., Lu, S. Q., \& Huang, Z. X. (2005). Cytokine expression during acute graft-versus-host disease after allogeneic peripheral stem cell transplantation.Bone Marrow Transplantation, 35 (12), 1179-1186. doi:10.1038/sj.bmt.1704972

Jung, I.-Y., Kim, Y.-Y., Yu, H.-S., Lee, M., Kim, S., \& Lee, J. (2018). CRISPR/Cas9-mediated knockout of DGK improves antitumor activities of human T cells. Cancer research, 78 (16), 4692-4703.

Jung, I.-Y., \& Lee, J. (2018). Unleashing the therapeutic potential of CAR-T cell therapy using gene-editing technologies. Molecules and Cells, 41 (8), 717.

Kim, D. W., \& Cho, J. Y. (2020). Recent Advances in Allogeneic CAR-T Cells. Biomolecules, 10 (2). doi:10.3390/biom10020263

Kim, S., Kim, D., Cho, S. W., Kim, J., \& Kim, J.-S. (2014). Highly efficient RNA-guided genome editing in human cells via delivery of purified Cas9 ribonucleoproteins. Genome research, 24 (6), 1012-1019. doi:10.1101/gr.171322.113

Kim, S., Koo, T., Jee, H. G., Cho, H. Y., Lee, G., Lim, D. G., . . Kim, J. S. (2018). CRISPR RNAs trigger innate immune responses in human cells. Genome Res, 28 (3), 367-373. doi:10.1101/gr.231936.117

Kornete, M., Marone, R., \& Jeker, L. T. (2018). Highly efficient and versatile plasmid-based gene editing in primary T cells. The Journal of Immunology, 200 (7), 2489-2501.

Koury, J., Lucero, M., Cato, C., Chang, L., Geiger, J., Henry, D., . . . Tran, A. (2018). Immunotherapies: Exploiting the Immune System for Cancer Treatment. J Immunol Res, 2018 , 9585614. doi:10.1155/2018/9585614

Koyama, S., Akbay, E. A., Li, Y. Y., Herter-Sprie, G. S., Buczkowski, K. A., Richards, W. G., . . Asahina, H. (2016). Adaptive resistance to therapeutic PD-1 blockade is associated with upregulation of alternative immune checkpoints. Nature communications, 7 (1), 1-9.

Li, C., Guan, X., Du, T., Jin, W., Wu, B., Liu, Y., . . Shattock, R. J. (2015). Inhibition of HIV-1 infection of primary CD4+ T-cells by gene editing of CCR5 using adenovirus-delivered CRISPR/Cas9. Journal of General Virology, 96 (8), 2381-2393. 
Li, D., Li, X., Zhou, W. L., Huang, Y., Liang, X., Jiang, L., . . Wang, W. (2019). Genetically engineered T cells for cancer immunotherapy. Signal Transduct Target Ther, 4 , 35. doi:10.1038/s41392-019-0070-9

Li, H., Yang, Y., Hong, W., Huang, M., Wu, M., \& Zhao, X. (2020). Applications of genome editing technology in the targeted therapy of human diseases: mechanisms, advances and prospects. Signal Transduct Target Ther, 5 (1), 1. doi:10.1038/s41392-019-0089-y

Liang, X., Potter, J., Kumar, S., Zou, Y., Quintanilla, R., Sridharan, M., . . Ranganathan, S. (2015). Rapid and highly efficient mammalian cell engineering via Cas9 protein transfection. Journal of biotechnology, 208 , 44-53.

Lino, C. A., Harper, J. C., Carney, J. P., \& Timlin, J. A. (2018). Delivering CRISPR: a review of the challenges and approaches. Drug delivery, 25 (1), 1234-1257.

Liu, X., Zhang, Y., Cheng, C., Cheng, A. W., Zhang, X., Li, N., . . Wang, H. (2017). CRISPR-Cas9-mediated multiplex gene editing in CAR-T cells. Cell Res, 27 (1), 154-157. doi:10.1038/cr.2016.142

Long, K. B., Young, R. M., Boesteanu, A. C., Davis, M. M., Melenhorst, J. J., Lacey, S. F., . . Fraietta, J. A. (2018). CAR T Cell Therapy of Non-hematopoietic Malignancies: Detours on the Road to Clinical Success.Front Immunol, 9 , 2740. doi:10.3389/fimmu.2018.02740

Long, L., Zhang, X., Chen, F., Pan, Q., Phiphatwatchara, P., Zeng, Y., \& Chen, H. (2018). The promising immune checkpoint LAG-3: from tumor microenvironment to cancer immunotherapy. Genes 83 cancer, 9 (5-6), 176 .

Luther, D. C., Lee, Y. W., Nagaraj, H., Scaletti, F., \& Rotello, V. M. (2018). Delivery approaches for CRISPR/Cas9 therapeutics in vivo: advances and challenges. Expert Opin Drug Deliv, 15 (9), 905-913. doi:10.1080/17425247.2018.1517746

Makarova, K. S., \& Koonin, E. V. (2015). Annotation and classification of CRISPR-Cas systems. In CRISPR (pp. 47-75): Springer.

Makarova, K. S., Wolf, Y. I., Iranzo, J., Shmakov, S. A., Alkhnbashi, O. S., Brouns, S. J., . . Horvath, P. (2019). Evolutionary classification of CRISPR-Cas systems: a burst of class 2 and derived variants. Nature Reviews Microbiology, 1-17.

Marofi, F., Motavalli, R., Safonov, V. A., Thangavelu, L., Yumashev, A. V., Alexander, M., ... Khiavi, F. M. (2021). CAR T cells in solid tumors: challenges and opportunities. Stem Cell Research \& Therapy, 12 (1), 81. doi:10.1186/s13287-020-02128-1

Maude, S. L., Laetsch, T. W., Buechner, J., Rives, S., Boyer, M., Bittencourt, H., . . Myers, G. D. (2018). Tisagenlecleucel in children and young adults with B-cell lymphoblastic leukemia. New England Journal of Medicine, 378 (5), 439-448.

Maude, S. L., Laetsch, T. W., Buechner, J., Rives, S., Boyer, M., Bittencourt, H., . . Grupp, S. A. (2018). Tisagenlecleucel in Children and Young Adults with B-Cell Lymphoblastic Leukemia. N Engl J Med, 378 (5), 439-448. doi:10.1056/NEJMoa1709866

Met, Ö., Jensen, K. M., Chamberlain, C. A., Donia, M., \& Svane, I. M. (2019). Principles of adoptive T cell therapy in cancer. Semin Immunopathol, 41 (1), 49-58. doi:10.1007/s00281-018-0703-z

Morgan, R. A., Dudley, M. E., \& Rosenberg, S. A. (2010). Adoptive cell therapy: genetic modification to redirect effector cell specificity. Cancer J, 16 (4), 336-341. doi:10.1097/PPO.0b013e3181eb3879

Mout, R., Ray, M., Lee, Y.-W., Scaletti, F., \& Rotello, V. M. (2017). In vivo delivery of CRISPR/Cas9 for therapeutic gene editing: progress and challenges. Bioconjugate chemistry, 28 (4), 880-884.

Nakazawa, T., Natsume, A., Nishimura, F., Morimoto, T., Matsuda, R., Nakamura, M., . . Park, Y.-S. (2020). Effect of CRISPR/Cas9-Mediated PD-1-Disrupted Primary Human Third-Generation CAR-T Cells 
Targeting EGFRvIII on In Vitro Human Glioblastoma Cell Growth. Cells, 9 (4), 998.

Neelapu, S. S., Locke, F. L., Bartlett, N. L., Lekakis, L. J., Miklos, D. B., Jacobson, C. A., . . Lin, Y. (2017). Axicabtagene ciloleucel CAR T-cell therapy in refractory large B-cell lymphoma. New England Journal of Medicine, 377 (26), 2531-2544.

Neelapu, S. S., Locke, F. L., Bartlett, N. L., Lekakis, L. J., Miklos, D. B., Jacobson, C. A., . . Go, W. Y. (2017). Axicabtagene Ciloleucel CAR T-Cell Therapy in Refractory Large B-Cell Lymphoma. $N$ Engl $J$ Med, 377 (26), 2531-2544. doi:10.1056/NEJMoa1707447

Park, J. H., Romero, F. A., Taur, Y., Sadelain, M., Brentjens, R. J., Hohl, T. M., \& Seo, S. K. (2018). Cytokine release syndrome grade as a predictive marker for infections in patients with relapsed or refractory B-cell acute lymphoblastic leukemia treated with chimeric antigen receptor T cells. Clinical Infectious Diseases, 67 (4), 533-540.

Poorebrahim, M., Melief, J., Pico de Coaña, Y., L. Wickström, S., Cid-Arregui, A., \& Kiessling, R. (2021). Counteracting CAR T cell dysfunction. Oncogene, 40 (2), 421-435. doi:10.1038/s41388-020-01501-x

Porter, D. L., Hwang, W. T., Frey, N. V., Lacey, S. F., Shaw, P. A., Loren, A. W., . . June, C. H. (2015). Chimeric antigen receptor $\mathrm{T}$ cells persist and induce sustained remissions in relapsed refractory chronic lymphocytic leukemia. Sci Transl Med, 7 (303), 303ra139. doi:10.1126/scitranslmed.aac5415

Rath, D., Amlinger, L., Rath, A., \& Lundgren, M. (2015). The CRISPR-Cas immune system: biology, mechanisms and applications. Biochimie, 117, 119-128.

Ren, J., Liu, X., Fang, C., Jiang, S., June, C. H., \& Zhao, Y. (2017). Multiplex Genome Editing to Generate Universal CAR T Cells Resistant to PD1 Inhibition. Clin Cancer Res, 23 (9), 2255-2266. doi:10.1158/10780432.Ccr-16-1300

Ren, J., Liu, X., Fang, C., Jiang, S., June, C. H., \& Zhao, Y. (2017). Multiplex genome editing to generate universal CAR T cells resistant to PD1 inhibition. Clinical cancer research, 23 (9), 2255-2266.

Ren, J., Zhang, X., Liu, X., Fang, C., Jiang, S., June, C. H., \& Zhao, Y. (2017). A versatile system for rapid multiplex genome-edited CAR T cell generation. Oncotarget, 8 (10), 17002.

Riese, M. J., Moon, E. K., Johnson, B. D., \& Albelda, S. M. (2016). Diacylglycerol Kinases (DGKs): Novel Targets for Improving T Cell Activity in Cancer. Frontiers in cell and developmental biology, 4 (108). doi:10.3389/fcell.2016.00108

Rodríguez-Lobato, L. G., Ganzetti, M., Fernández de Larrea, C., Hudecek, M., Einsele, H., \& Danhof, S. (2020). CAR T-Cells in Multiple Myeloma: State of the Art and Future Directions. Frontiers in Oncology, 10 (1243). doi:10.3389/fonc. 2020.01243

Roth, T. L., Puig-Saus, C., Yu, R., Shifrut, E., Carnevale, J., Li, P. J., . . Marson, A. (2018). Reprogramming human T cell function and specificity with non-viral genome targeting. Nature, 559 (7714), 405-409. doi:10.1038/s41586-018-0326-5

Rupp, L. J., Schumann, K., Roybal, K. T., Gate, R. E., Chun, J. Y., Lim, W. A., \& Marson, A. (2017). CRISPR/Cas9-mediated PD-1 disruption enhances anti-tumor efficacy of human chimeric antigen receptor T cells.Scientific reports, 7 (1), 1-10.

Sadelain, M. (2017). CD19 CAR T Cells. Cell, 171 (7), 1471. doi:10.1016/j.cell.2017.12.002

Sadeqi Nezhad, M., Seifalian, A., Bagheri, N., Yaghoubi, S., Karimi, M. H., \& Adbollahpour-Alitappeh, M. (2020). Chimeric Antigen Receptor Based Therapy as a Potential Approach in Autoimmune Diseases: How Close Are We to the Treatment? Front Immunol, 11 , 603237. doi:10.3389/fimmu.2020.603237

Salas-Mckee, J., Kong, W., Gladney, W. L., Jadlowsky, J. K., Plesa, G., Davis, M. M., \& Fraietta, J. A. (2019). CRISPR/Cas9-based genome editing in the era of CAR T cell immunotherapy. Human vaccines $\&$ 
immunotherapeutics, 15 (5), 1126-1132.

Schumann, K., Lin, S., Boyer, E., Simeonov, D. R., Subramaniam, M., Gate, R. E., . . Marson, A. (2015). Generation of knock-in primary human T cells using Cas9 ribonucleoproteins. Proc Natl Acad Sci U S A, 112 (33), 10437-10442. doi:10.1073/pnas.1512503112

Seki, A., \& Rutz, S. (2018). Optimized RNP transfection for highly efficient CRISPR/Cas9-mediated gene knockout in primary T cells. J Exp Med, 215 (3), 985-997. doi:10.1084/jem.20171626

Seliger, B. (2019). Basis of PD1/PD-L1 therapies. Journal of Clinical Medicine, 8 (12), 2168.

Sharpe, M., \& Mount, N. (2015). Genetically modified T cells in cancer therapy: opportunities and challenges. Disease models $\&$ mechanisms, 8 (4), 337-350.

Shen, B., Zhang, W., Zhang, J., Zhou, J., Wang, J., Chen, L., . . . Huang, X. (2014). Efficient genome modification by CRISPR-Cas9 nickase with minimal off-target effects. Nature methods, 11 (4), $399-402$.

Singh, N., Perazzelli, J., Grupp, S. A., \& Barrett, D. M. (2016). Early memory phenotypes drive $\mathrm{T}$ cell proliferation in patients with pediatric malignancies. Sci Transl Med, 8 (320), $320 \mathrm{ra323.}$ doi:10.1126/scitranslmed.aad5222

Sorek, R., Lawrence, C. M., \& Wiedenheft, B. (2013). CRISPR-mediated adaptive immune systems in bacteria and archaea. Annual review of biochemistry, 82 , 237-266.

Stenger, D., Stief, T. A., Kaeuferle, T., Willier, S., Rataj, F., Schober, K., . . . Feuchtinger, T. (2020). Endogenous TCR promotes in vivo persistence of CD19-CAR-T cells compared to a CRISPR/Cas9-mediated TCR knockout CAR. Blood, 136 (12), 1407-1418. doi:10.1182/blood.2020005185

Stenger, D., Stief, T. A., Käuferle, T., Willier, S., Rataj, F., Schober, K., . . . Grunewald, T. (2020). Endogenous TCR promotes in vivo persistence of CD19-CAR-T cells compared to a CRISPR/Cas9-mediated TCR knockout CAR. Blood .

Sterner, R. M., Sakemura, R., Cox, M. J., Yang, N., Khadka, R. H., Forsman, C. L., . . Hefazi, M. (2019). GM-CSF inhibition reduces cytokine release syndrome and neuroinflammation but enhances CAR-T cell function in xenografts. Blood, The Journal of the American Society of Hematology, 133 (7), $697-709$.

Tang, N., Cheng, C., Zhang, X., Qiao, M., Li, N., Mu, W., . . . Wang, H. (2020). TGF- $\beta$ inhibition via CRISPR promotes the long-term efficacy of CAR T cells against solid tumors. JCI insight, 5 (4).

Torikai, H., Reik, A., Soldner, F., Warren, E. H., Yuen, C., Zhou, Y., . . . Cooper, L. J. (2013). Toward eliminating HLA class I expression to generate universal cells from allogeneic donors. Blood, 122 (8), 13411349. doi:10.1182/blood-2013-03-478255

Torikai, H., Reik, A., Yuen, C., Zhou, Y., Kellar, D., Huls, H., . . . Cooper, L. (2010). HLA and TCR Knockout by Zinc Finger Nucleases: Toward "off-the-Shelf" Allogeneic T-Cell Therapy for CD19+ Malignancies.Blood, 116 (21), 3766-3766. doi:10.1182/blood.V116.21.3766.3766

Townsend, M. H., Bennion, K., Robison, R. A., \& O’Neill, K. L. (2020). Paving the way towards universal treatment with allogenic $\mathrm{T}$ cells.Immunologic Research , 1-8.

Turley, S. J., Cremasco, V., \& Astarita, J. L. (2015). Immunological hallmarks of stromal cells in the tumour microenvironment. Nature Reviews Immunology, 15 (11), 669-682.

Wang, M., Munoz, J., Goy, A., Locke, F. L., Jacobson, C. A., Hill, B. T., . . . Reagan, P. M. (2020). KTE-X19 CAR T-Cell Therapy in Relapsed or Refractory Mantle-Cell Lymphoma. N Engl J Med, 382 (14), 1331-1342. doi:10.1056/NEJMoa1914347

Wang, W., Ye, C., Liu, J., Zhang, D., Kimata, J. T., \& Zhou, P. (2014). CCR5 gene disruption via lentiviral vectors expressing Cas9 and single guided RNA renders cells resistant to HIV-1 infection. PloS one, 9 (12), e115987. 
Wei, T., Cheng, Q., Min, Y.-L., Olson, E. N., \& Siegwart, D. J. (2020). Systemic nanoparticle delivery of CRISPR-Cas9 ribonucleoproteins for effective tissue specific genome editing. Nature communications, 11 (1), 3232. doi:10.1038/s41467-020-17029-3

Wherry, E. J., \& Kurachi, M. (2015). Molecular and cellular insights into T cell exhaustion. Nat Rev Immunol, 15 (8), 486-499. doi:10.1038/nri3862

Wu, X., Kriz, A. J., \& Sharp, P. A. (2014). Target specificity of the CRISPR-Cas9 system. Quantitative biology, $2(2), 59-70$.

Xiao-Jie, G. E. L., Li-Juan, J., Koo, T., \& Kim, J.-S. (2017). Therapeutic applications of CRISPR RNAguided genome editing.Briefings in Functional Genomics, 16 (1), 38-45.

Xu, X., Wan, T., Xin, H., Li, D., Pan, H., Wu, J., \& Ping, Y. (2019). Delivery of CRISPR/Cas9 for therapeutic genome editing. The Journal of Gene Medicine, 21 (7), e3107.

Yazdanifar, M., Zhou, R., Grover, P., Williams, C., Bose, M., Moore, L. J., . . . Mukherjee, A. P. (2019). Overcoming Immunological Resistance Enhances the Efficacy of A Novel Anti-tMUC1-CAR T Cell Treatment against Pancreatic Ductal Adenocarcinoma. Cells, 8 (9). doi:10.3390/cells8091070

Yazdanifar, M., Zhou, R., \& Mukherjee, P. (2016). Emerging immunotherapeutics in adenocarcinomas: A focus on CAR-T cells. Curr Trends Immunol, 17, 95-115.

Zak, K. M., Kitel, R., Przetocka, S., Golik, P., Guzik, K., Musielak, B., . . . Holak, T. A. (2015). Structure of the complex of human programmed death 1, PD-1, and its ligand PD-L1. Structure, 23 (12), 2341-2348.

Table 1. Application of the CRISPR/Cas9 system in CAR T-cell performances.

\begin{tabular}{|c|c|c|c|c|c|c|c|}
\hline $\begin{array}{l}\text { Preclinical } \\
\text { Study }\end{array}$ & $\begin{array}{l}\text { CRISPR } \\
\text { Target } \\
\text { Regions }\end{array}$ & $\begin{array}{l}\text { CRISPR } \\
\text { Delivery } \\
\text { Method }\end{array}$ & $\begin{array}{l}\text { CAR T } \\
\text { Product }\end{array}$ & $\begin{array}{l}\text { CAR T } \\
\text { Target- } \\
\text { Antigen }\end{array}$ & $\begin{array}{l}\text { CAR T } \\
\text { delivery } \\
\text { Method }\end{array}$ & Overview & Year [Ref] \\
\hline $\begin{array}{l}\text { Xenograft } \\
\text { model of } \\
\text { childhood } \\
\text { ALL }\end{array}$ & $\begin{array}{l}\text { TCR- } \beta- \\
\text { chain }\end{array}$ & $\begin{array}{l}\text { RNP } \\
\text { Electropo }\end{array}$ & $\begin{array}{l}\mathrm{TCR}^{-} \mathrm{CAR} \\
\mathrm{nT-cells}\end{array}$ & CD19 & Retroviral & $\begin{array}{l}\text { TCR } \\
\text { knockout } \\
\text { CAR-T cells } \\
\text { are a } \\
\text { promising } \\
\text { option for } \\
\text { tertiary } \\
\text { patients and } \\
\text { showed no } \\
\text { alloreactiv- } \\
\text { ity, despite } \\
\text { their low } \\
\text { persistency. }\end{array}$ & $\begin{array}{l}2020 \\
\text { (Stenger, } \\
\text { Stief, } \\
\text { Käuferle, et } \\
\text { al., 2020) }\end{array}$ \\
\hline
\end{tabular}




\begin{tabular}{|c|c|c|c|c|c|c|c|}
\hline $\begin{array}{l}\text { Preclinical } \\
\text { Study }\end{array}$ & $\begin{array}{l}\text { CRISPR } \\
\text { Target } \\
\text { Regions }\end{array}$ & $\begin{array}{l}\text { CRISPR } \\
\text { Delivery } \\
\text { Method }\end{array}$ & $\begin{array}{l}\text { CAR T } \\
\text { Product }\end{array}$ & $\begin{array}{l}\text { CAR T } \\
\text { Target- } \\
\text { Antigen }\end{array}$ & $\begin{array}{l}\text { CAR T } \\
\text { delivery } \\
\text { Method }\end{array}$ & Overview & Year [Ref] \\
\hline $\begin{array}{l}\text { Humanized } \\
\text { murine } \\
\text { model of } \\
\text { glioma }\end{array}$ & $\begin{array}{l}\text { TRAC, } \\
\beta 2 \mathrm{M}, \text { and } \\
\text { PD-1 }\end{array}$ & $\begin{array}{l}\text { RNP } \\
\text { Electroporatio }\end{array}$ & $\begin{array}{l}\text { Universal } \\
\text { nCAR-T cells } \\
\text { resistant to } \\
\text { PD-L1 }\end{array}$ & EGFRvIII & AAV6 vector & $\begin{array}{l}\text { CRISPR/Cas9 } \\
\text { successfully } \\
\text { generated } \\
\text { universal } \\
\text { CAR-T cells } \\
\text { and enables } \\
\text { them to } \\
\text { resist } \\
\text { against } \\
\text { PD-L1. This } \\
\text { CAR T-cell } \\
\text { showed } \\
\text { prolong } \\
\text { survival and } \\
\text { anti-tumor } \\
\text { activity in } \\
\text { mice. }\end{array}$ & $\begin{array}{l}2019 \text { (Choi } \\
\text { et al., 2019) }\end{array}$ \\
\hline $\begin{array}{l}\text { Humanized } \\
\text { murine } \\
\text { model of } \\
\text { leukemia }\end{array}$ & TRAC & $\begin{array}{l}\text { Cas9 mRNA } \\
\text { Electropora- } \\
\text { tion and } \\
\text { gRNA } \\
\text { lentiviral } \\
\text { delivery }\end{array}$ & $\begin{array}{l}\text { TCR }^{-} \text {CAR } \\
\text { T-cells }\end{array}$ & CD19 & $\begin{array}{l}\text { Lentiviral } \\
\text { coupling } \\
\text { CAR and } \\
\text { gRNA }\end{array}$ & $\begin{array}{l}\text { Separated } \\
\text { delivery of } \\
\text { CRISPR } \\
\text { components } \\
\text { may bring } \\
\text { several } \\
\text { advantages, } \\
\text { including } \\
\text { time-saving } \\
\text { and low } \\
\text { immuno- } \\
\text { genicity. } \\
\text { TCR- } \\
\text { CAR-T cells } \\
\text { mediated } \\
\text { highly } \\
\text { effective } \\
\text { leukemic } \\
\text { eradication } \\
\text { with less } \\
\text { evidence of } \\
\text { exhaustion }\end{array}$ & $\begin{array}{l}2018 \\
\text { (Georgiadis } \\
\text { et al., 2018) }\end{array}$ \\
\hline
\end{tabular}




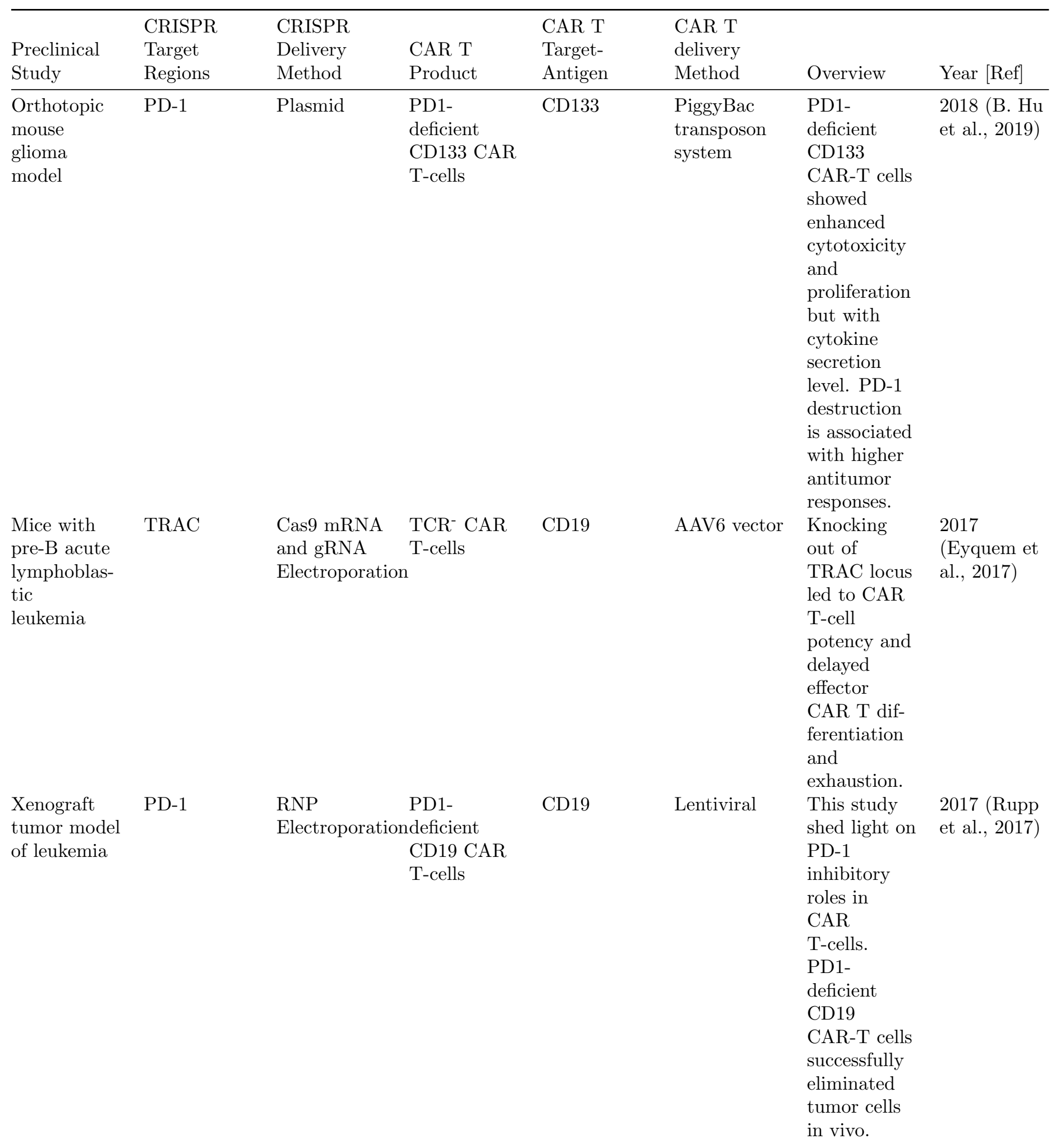




\begin{tabular}{|c|c|c|c|c|c|c|}
\hline $\begin{array}{l}\text { Preclinical } \\
\text { Study }\end{array}$ & $\begin{array}{l}\text { CRISPR } \\
\text { Target } \\
\text { Regions }\end{array}$ & $\begin{array}{ll}\text { CRISPR } & \\
\text { Delivery } & \text { CAR T } \\
\text { Method } & \text { Product }\end{array}$ & $\begin{array}{l}\text { CAR T } \\
\text { Target- } \\
\text { Antigen }\end{array}$ & $\begin{array}{l}\text { CAR T } \\
\text { delivery } \\
\text { Method }\end{array}$ & Overview & Year [Ref] \\
\hline $\begin{array}{l}\text { Mice with B } \\
\text { cell } \\
\text { precursor } \\
\text { leukemia } \\
\text { (Nalm6 or } \\
\text { Nalm6- } \\
\text { PDL1 tumor } \\
\text { cells) }\end{array}$ & $\begin{array}{l}\text { TCR, } \beta 2 \mathrm{M}, \\
\text { and PD1 }\end{array}$ & $\begin{array}{lc}\text { Cas9 and } & \text { Universal } \\
\text { gRNAs RNA } & \text { CAR-T cells } \\
\text { Electroporationresistant to } & \text { PD-L1 }\end{array}$ & $\begin{array}{l}\text { PSCA and } \\
\text { CD19 }\end{array}$ & Lentiviral & $\begin{array}{l}\text { TCR and } \\
\beta 2 \mathrm{M} \\
\text { knockout } \\
\text { CAR-T cells } \\
\text { can be } \\
\text { considered } \\
\text { as universal } \\
\text { CAR } \\
\text { T-cells. and } \\
\text { PD1 } \\
\text { knockout led } \\
\text { to enhanced } \\
\text { in vivo } \\
\text { anti-tumor } \\
\text { activity. }\end{array}$ & $\begin{array}{l}2016 \\
\text { (Jiangtao } \\
\text { Ren, } \\
\text { Xiaojun Liu, } \\
\text { et al., 2017) }\end{array}$ \\
\hline
\end{tabular}

Abbreviations : $\mathrm{T}$ cell receptor (TCR), T-cell receptor $\alpha$ constant (TRAC ), $\beta$-2 microglobulin ( $\beta 2 \mathrm{M})$, programmed cell death protein 1 (PD-1), and adeno-associated virus (AAV).

Table 2 . CAR T-cell clinical trials for brain tumors

\begin{tabular}{llll}
\hline Conditions & Target antigen & Participants & Sponsor \\
\hline Glioblastoma & EGFRvIII & 18 & National Cancer Institute \\
Glioblastoma & EGFRvIII & 7 & University of Pennsylvania \\
R/R Brain Neoplasm & IL13R $\alpha 2$ & 18 & City of Hope Medical Center \\
R/R Glioblastoma & IL13R $\alpha 2$ & 60 & City of Hope Medical Center \\
Diffuse Intrinsic Pontine and Midline Glioma & B7-H3 & 70 & Seattle Children's Hospital \\
R/R Glioblastoma & B7-H3 & 12 & Zhejiang University School of Medicine \\
R/R Brain Tumor & HER2 & 28 & Baylor College of Medicine \\
Recurrent Glioblastoma & MMP2 & 36 & City of Hope Medical Center \\
High Grade Glioma & GD2 & 32 & Baylor College of Medicine \\
\hline
\end{tabular}

Abbreviation: R/R, Recurrent and Refractory

\section{Caption for Figures}

Figure 1. CRISPR/Cas9 mechanism of action . The type II CRISPR system is armed with CRISPRassociated protein, Cas9, that has two distinct domains named HNH-nuclease and RuvC-like nuclease, which produce double-stranded breaks (DSBs) in DNA of interest. The trans-activating CRISPR RNA (tracrRNA) and crRNA combine and form a single-guided RNA (sgRNA), a 17-20 nucleotide sequence that binds to the target DNA. sgRNA has a PAM sequence after the 3' end of its sequence, guiding the Cas9 protein to generate DSBs in desired DNA. Next, DSBs undergo two different mechanisms of repairs, homologous directed repair (HDR) suitable for knocking in a specific donor DNA in the target DNA, and the non-homologous end joining (NHEJ) ideal for knocking out the target DNA.

Figure 2. The general workflow for CRISPR Cas9-based CAR T-cell manufacturing . Peripheral blood mononuclear cells (PBMCs) obtain from the patient. Anticoagulants, red blood cells, and platelets contaminate the product would be removed in a washing step. Afterward, enrichment or depletion processes 
would be done for specific cell subsets. Next, T cells get activated by using different procedures, including monoclonal antibodies with interleukins (IL-2, IL-7, 1L-15), anti-CD3/CD28 antibody-coated magnetic beads, soluble CD3 antibody, artificial antigen-presenting cells (K562 cell lines), plate-bound antibody, and adhesion molecules (CD2). T cell activation pathways in cell culture media provide both the primary and co-stimulatory signals required to activate the desired $\mathrm{T}$ cells. In this stage, CAR transgene may be delivered into the activated $\mathrm{T}$ cells by different approaches, including viral (lentivirus and retrovirus) and non-viral (electroporation of naked DNA and transposon/transposase) methods or CRISPR/Cas9 system may be applied first into the T cells to target the gene of interest. Subsequently, the activated T cells undergo an expansion process for a certain period (depending on the methods of expansion, such as using static culture bags or dynamic culture vessels or rotating bioreactors). If CAR transgene first introduced into the $\mathrm{T}$ cells with no CRISPR/Cas9 transformation, (a), then the modified T-cells will be introduced with CRISPR/Cas9 components, (b), to target the DNA of interest in CAR T cells. There are different approaches to deliver CRISPR/Cas9: (I) transfection with DNA plasmid encoding both Cas9 protein and sgRNA, (II) the viral delivery using lentivirus and retrovirus, and non-integrating viruses such as adenovirus and adenovirus-associated virus (AAV), (III) transfection with mRNA that encodes Cas9 or separate sgRNA, and (IV) CRISPR delivery via Cas9 protein with guide RNA (ribonucleoprotein (RNP) complex). Finally, the prepared modified T-cells are calculated according to the patient's condition and type of cancer, then ready to introduce the engineered $\mathrm{T}$ cells to the patient through IV injection or intratumoral administration.

Figure 3. Representation of CRISPR-edited CAR-T cell . CRISPR/Cas9 genome editing technology improved CAR-T cells performance in various ways, including targeting the Diacylglycerol kinases (DGKs) gene, and knocking out the TCR, HLA, and inhibitory receptors.

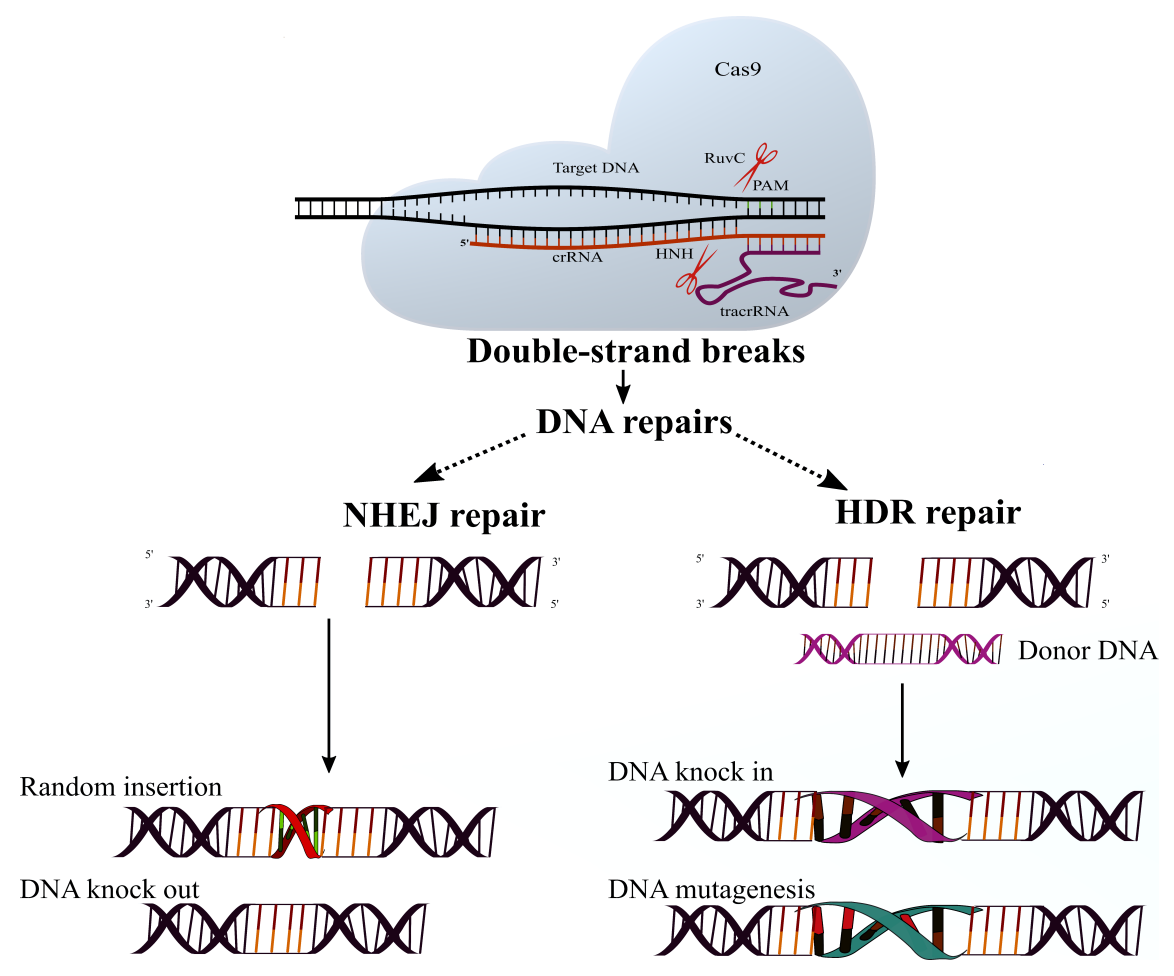




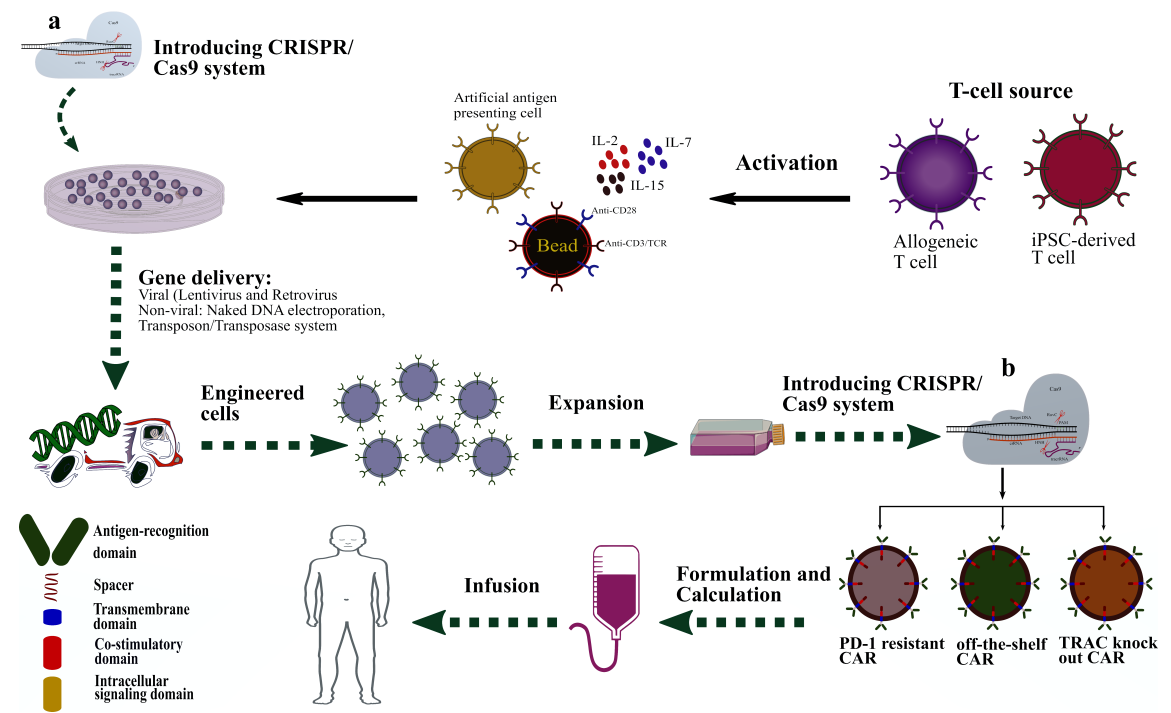

TCR knocked-out

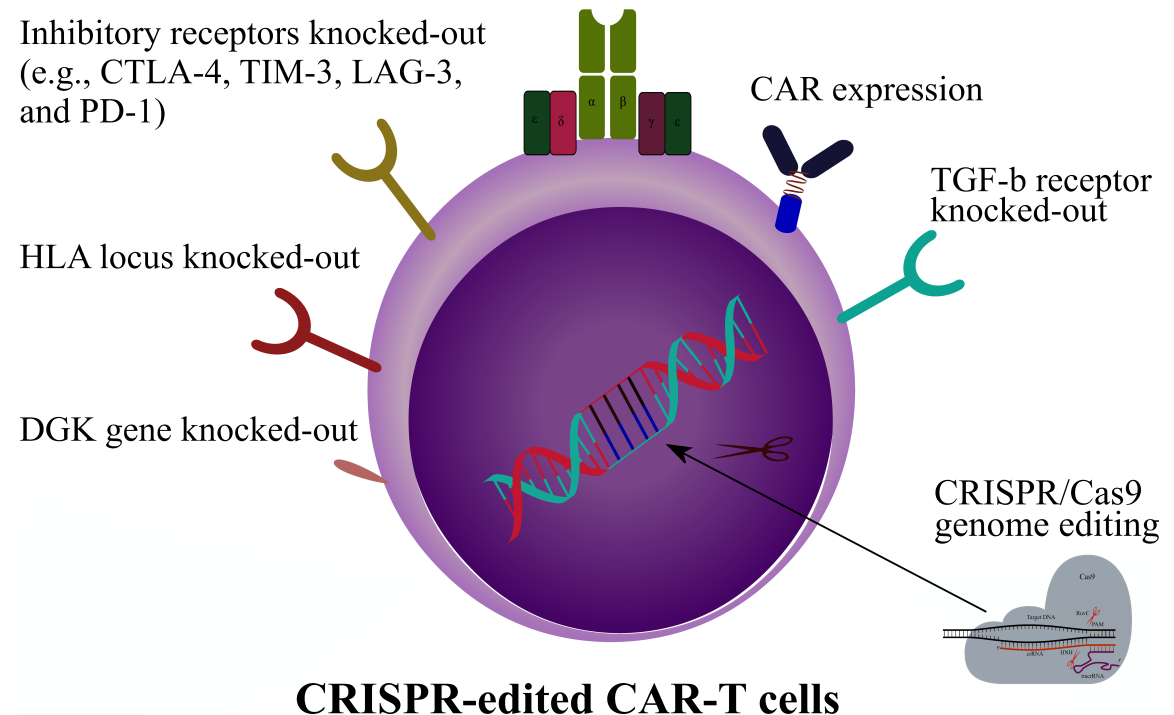

